\title{
A variação você e cê no sertão alagoano
}

\author{
Suziane de Oliveira Porto Silva ${ }^{1}$
}

Elyne Giselle de Santana Lima Aguiar Vitórioº

\section{Resumo}

Esta pesquisa analisa a realizaçãa tu, você e cê na posição de sujeito no sertão alagoano. Para tanto, recorremos à Sociolinguística Variacionista (LABOV, 2008) e ao banco de dados do Projeto Lusa e utilizamos - programa GoldV arb X para a análise estatística dos dados. De acordo com os resultados obtidos, verificamos que o pronome tu apresenta apenas três realizações, o que pode ser um indício de que seu uso não seja a primeira opção da comunidade para a referência a segunda pessoa do singular na posição de sujeito. Em relação ao uso de você e cê, obtivemos um percentual de 94\% de você versus $6 \%$ de cê, sendo essa variação condicionada pelas variáveis escolaridade e paralelismo formal. Esses resultados nos levam a argumentar que, no sertão alagoano, a representação da segunda pessoa do singular na posição de sujeito se encaixa no subsistema tu/você sem concordância (SCHERRE et al., 2015).

Palavras-chave: Sociolinguística. Variação.

Pronomes. Fala. Sertão alagoano

\footnotetext{
${ }^{1}$ Graduada em Letras pela UFAL/Campus do Sertão e mestranda em Linguística pelo PPGLL da UFAL.

${ }^{2}$ Doutora em Linguística e Professora de Língua Portuguesa e Linguística do curso de Letras da UFAL/Campus do Sertão.
} 


\section{Introdução}

A forma pronominal você teve origem a partir da forma de tratamento Vossa Mercê, que tem passado pelos seguintes estágios de mudança: vossa mercê $>$ vossemecê $>$ vosmecê $>$ vosm' $c \hat{e}>\operatorname{vosc\hat {e}}>$ você $>$ oce $>c \hat{e}$. Sendo usada inicialmente para fazer tratamento ao rei, de forma a exaltar as qualidades e superioridade dele, Vossa Mercê surgiu entre os séculos XIV e XV. Porém, na segunda metade do século XV, a forma Vossa Mercê acabou sendo vulgarizada, deixando de ser utilizada exclusivamente em referência a quem se mantinha respeito, assim, a forma de tratamento ao rei foi substituída por outras formas nominais (MACHADO, 2011).

A partir da vulgarização do uso da forma de tratamento Vossa Mercê, algumas alterações fonéticas foram surgindo até chegar à forma utilizada nos dias atuais - você. Vitral (1996) considera essas alterações com um processo de gramaticalização, ou seja, um nome (Vossa Mercê) transforma-se em um pronome (você), que atualmente encontra-se em variação com as formas ocê e cêem algumas regiões do país (SCHERRE et al. 2015). Dessa forma, podemos considerar que, nos dias atuais, além do pronome tu, conservado do quadro pronominal latino como segunda pessoa do singular, podemos ter também o pronome você e suas variantes ocê e cê.

Neste estudo, analisamos a variação dos pronomes de segunda pessoa do singular tu/você e você/cê na posição de sujeito na língua usada no sertão de Alagoas, de forma a estabelecer uma correlação entre a sociedade e a estrutura linguística ${ }^{3}$. Para tanto, realizamos uma análise quantitativa dos dados com o intuito de responder as seguintes questões: há variação dos pronomes $t u / v o c \hat{e}$ e você/cê na amostra analisada? Supondo a existência da variação, há condicionamento dos grupos de fatores linguísticos tipo de referência, tipo de discurso e paralelismo formal e dos grupos de fatores sociais sexo/gênero, faixa etária e escolaridade?

Como respostas provisórias às questões acima formuladas, propomos as seguintes hipóteses: partindo do pressuposto de que a língua apresenta uma heterogeneidade ordenada, acreditamos não só que o pronome tu coexiste com o pronome você na comunidade pesquisada, assim como o pronome você coexiste com a sua variante $c \hat{e}$, como

\footnotetext{
${ }^{3}$ Esta pesquisa pertence ao projeto de pesquisa A Lingua Usada no Sertão Alagoano (Lusa), desenvolvido na UFAL - Campus Sertão, sob a coordenação da Prof ${ }^{a}$. Dra ${ }^{a}$. Elyne Vitório e está cadastrado e aprovado no Comitê de Ética e Pesquisa da UFAL, sob o número do parecer 1.073.208. Todos os informantes entrevistados no Projeto Lusa assinaram o Termo de Consentimento Livre e Esclarecido.
} 
também que os grupos de fatores linguísticos e sociais selecionados condicionam a realização dos pronomes tu, vocêe cê na comunidade de fala do sertão de Alagoas.

Para confirmar ou refutar as hipóteses apresentadas sobre a análise dos pronomes de $2^{\mathrm{a}}$ pessoa do singular na posição de sujeito no sertão de Alagoas, apresentamos os objetivos específicos que norteiam esta pesquisa, a saber, analisar se há variação dos pronomes $t u / v o c \hat{e}$ e você/cê no sertão alagoano, verificar a frequência de uso desses pronomes na comunidade pesquisada, descrever os fatores linguísticos e/ou sociais que condicionam as realizações de $t u / v o c \hat{e}$ e você/cê e encaixar a variação em análise em algum subsistema proposto por Scherre et al. (2015).

A fim de cumprir o proposto enunciado, apresentamos, na seção “A variação da $2^{\mathrm{a}}$ pessoa do singular no PB", o comportamento variável dos pronomes tu e você no português brasileiro (PB), conforme o mapeamento proposto por Scherre et al. (2015). Destacamos, na seção "Aporte teórico-metodológico", os aspectos concernentes aos pressupostos teóricos e metodológicos da pesquisa. Na seção "Descrição e análise dos dados", analisamos e comentamos os resultados obtidos. Nas "Considerações finais", encerramos as discussões levantadas acerca da realização de $t u / v o c \hat{e} / c \hat{e}$ no sertão de Alagoas.

\section{A variação da $2^{\mathrm{a}}$ pessoa do singular no $\mathrm{PB}$}

Estudos sociolinguísticos sobre a realização da $2^{\mathrm{a}}$ pessoa do singular em algumas variedades do $\mathrm{PB}$ nos mostram um comportamento variável entre as formas tu, você e $c \hat{e}$ (PAREDES SILVA, 2003; MODESTO, 2006; MACHADO, 2011; SOUZA, 2012; SCHERRE et al. 2015; ROCHA; SANTOS; SOUSA, 2016, entre outros). A predominância de uma ou outra forma pronominal varia de acordo com algumas variáveis sociais como escolaridade, sexo/gênero, faixa etária, assim como a região em que o falante está inserido, bem como variáveis linguísticas como o tipo de discurso, tipo de referência, formalidade do discurso e concordância verbal.

Scherre et al. (2015) nos trazem um mapeamento sociolinguístico das realizações das formas tu e você nas variedades do PB analisadas e nos fazem entender como essa variação é realizada em todo o território nacional, como podemos observar no mapa 1: 


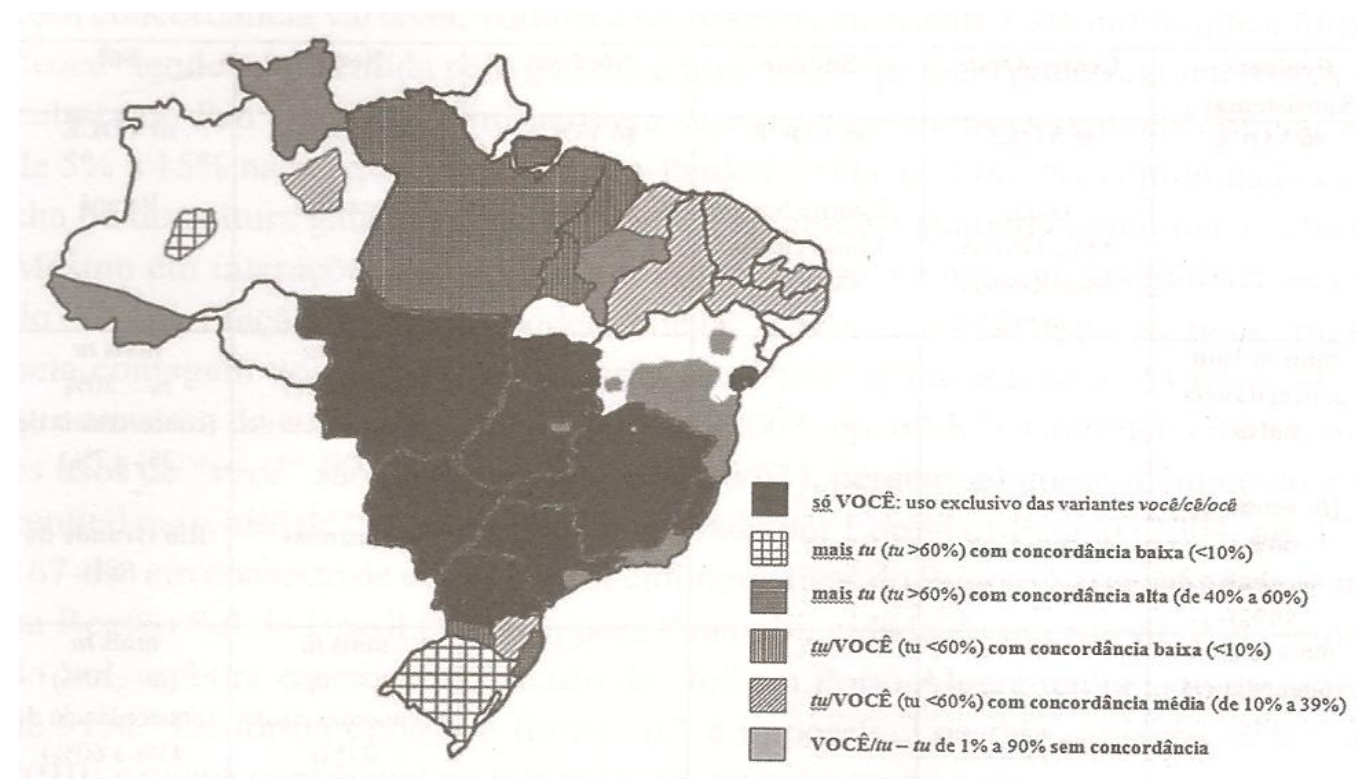

Mapa 1: mapeamento de tu e você no português brasileiro. Fonte: Scherre et al. (2015, p. 142).

Como podemos observar, o mapeamento realizado pelos autores abrange todo o país, o que nos possibilita ter uma noção de como a variação está distribuída em nosso território, conseguindo conhecer melhor a realidade linguística brasileira. O mapeamento é composto por seis subsistemas, sendo eles: só você, mais tu com concordância baixa, mais tu com concordância alta, tu/você com concordância baixa, tu/você com concordância média e você/tu sem concordância. Porém, o mapeamento realizado por Scherre et al. (2015) apresenta regiões em que não há uma descrição dessa variação, como é o caso dos estados de Alagoas, Rio Grande do Norte, Amapá, Rondônia e parte dos estados da Bahia, Tocantins e Amazonas.

O subsistema só você, como podemos observar no mapa, diz respeito ao uso exclusivo das variantes você/ $c \hat{e} / o c \hat{e}$, estando presente nas regiões Centro-Oeste, Norte, Nordeste, Sudeste e Sul, porém, com maior concentração no Centro-Oeste. Scherre et al. (2015) constataram que existem distinções nas capitais Belo Horizonte/MG, Vitória/ES e São Paulo/SP, com Belo Horizonte apresentando o cê como forma mais frequente, Vitória com o você e São Paulo apresentando um equilíbrio entre você e cê. Apesar do ocê ser considerado característico da fala mineira ou rural seu percentual de uso foi baixo nas amostras analisadas, prevalecendo o uso do cê. A concentração desse subsistema na região Centro-Oeste pode ser percebida também através do estudo de Andrade (2004) que nos mostra $57 \%$ de uso do você e $25 \%$ do cê, como também na pesquisa de Dias (2007), que apresenta uma ocorrência de $87 \%$ do $c \hat{e} / v o c \hat{e}$, conforme podemos observar nos exemplos (1): 
(1)

JB A., C $\hat{E}$ vai ficar na casa do D.?

AC Vou.

JB $\mathbf{C E}$ tem... $\mathbf{C} \hat{\mathbf{E}}$ tem família lá também, né?

AC Tenho.

AC [para JB] Ah! Ela sai na hora dela ... dela jogar. Por que que $\mathbf{C} \hat{\mathbf{E}}$ não sai depois, CÊ joga e depois...

CS A., C $\hat{\mathbf{E}}$ ta morenona, ein? Assim, perto de mim TU é branquela, mas $\varnothing$ tá morenona perto das meninas ... J. é VOCÊ, ô enrolada! (DIAS, 2007, p. 4).

O subsistema $t u$ com concordância baixa é encontrado nos extremos Norte e Sul do país. Segundo o estudo de Loregian-Penkal (2004), na região Sul, nas cidades Rio Grande do Sul, Porto Alegre, Flores da Cunha, Panambi, São Borjas e Pelotas, a predominância do pronome tu é superior a $85 \%$ com concordância abaixo de $7 \%$. Scherre et al. (2015) também mostram os resultados de Ilari et al. (1996) que apresentam que em 12 casos de tu registrados no corpus mínimo do Nurc, 11 deles se encontram na fala de Porto Alegre. Já na região Norte, em Tefé/AM, foi registrado um uso médio do tu com $65 \%$ e concordância de 4\%. Como apenas Tefé foi analisada nesse subsistema, os autores não descartam a possibilidade de haver uma reorganização dos dados.

O subsistema tu com concordância alta é fortemente percebido no estado do Pará e em Santa Catarina, com uso médio do tu acima de 60\% e concordância entre 40\% e 60\%. Scherre et al. (2015) nos mostram que, em Florianópolis/SC e Ribeirão da Ilha/SC, há a predominância do pronome tu com concordância entre 43\% e 60\%. Já na região Norte, os autores mostram que, em Belém/PA, a presença do tu é alta, aproximando-se de $80 \%$, segundo o estudo de Soares e Leal (1993), porém, nele os percentuais de concordância não são apresentados. Os autores também afirmam que em dados do Projeto Mocajumba (CAMPOS, 2006) no Pará é possível encontrar 43\% de concordância na fala da entrevistadora. 
O subsistema $t u / v o c e ̂$ com concordância baixa é facilmente encontrado na região Nordeste e Sul. A região Nordeste tem o estado do Maranhão como representante, apresentando $37 \%$ de uso do $t u$ com 3\% de concordância em Pinheiro, segundo o estudo de Alves (2010), feito a partir de dados do Projeto Atlas Linguístico do Maranhão (Alima) e $29 \%$ de uso do tu com 8\% de concordância em Imperatriz segundo o estudo de Herênio (2006), realizado a partir de entrevistas sociolinguísticas. Na região Sul, o estado que representa esse subsistema é Santa Catarina, na cidade de Chapecó, apresentando 50\% de uso do tu com variação de $2 \%$, segundo os dados do Projeto Varsul (LOREGIANPENKAL, 2004). Em relação ao uso do vocêl cê/ocê, o estudo de Alves (2010) nos mostra os percentuais de $51,1 \%, 8,5 \%$ e $2,1 \%$, respectivamente. Como podemos observar no exemplo (2):

INQ. - E quando tu tomas conhecimento de que um amigo casou, como comentas com esse amigo a novidade?

INF. - Ah, se eu encontrei ele, eu digo assim: “Ah, meu amigo, tu já ta casado, cê casô, desejo boa sorte, felicidade..."

INQ. - É, mas imagina que ele casou, mas na época ele nem te convidou, como é que tu dizes pra ele?

INF. - Ah, sim, eu chego e digo: "Ah, rapaz, tu casô, não me convidô pro teu casamento".

INQ. - É, mas eu... Tu queres dizer pra ele que outra pessoa te disse?

INF. - É, é, “Tu me, tu não me convido, tu casaste, mas outra pessoa me disse que tu casô, que cê ta casado".

(ALVES, 2010, p. 103)

Já o subsistema tu/você com concordância média é encontrado nas regiões Nordeste, Norte e Sul. Na região Nordeste, os estados representantes são Maranhão, Piauí, Ceará, Paraíba e Pernambuco. No Maranhão, o uso do tu aparece com 39\% e 29\% de concordância, enquanto, no Ceará, o uso é de $34 \%$ com concordância de $24 \%$. Na Paraíba, 
não existem percentuais conhecidos em relação ao uso do tu, porém, a concordância foi registrada em 23\%. Em Pernambuco, o uso do tu apareceu com 20\% de uso e concordância de $67 \%$. No Piauí, constata-se que existe o uso do tu abaixo de $60 \%$, porém, não se sabe exatamente quais são os percentuais. Na região Norte, registrou-se $38 \%$ do uso do tu com concordância próxima a $28 \%$. E, na região Sul, pode ser observado, a partir de dois estudos diferentes, que, em Santa Catarina, o uso do th é de $27 \%$ e $23 \%$ de concordância, enquanto que, em Blumenau, é de 38\% e 29\% respectivamente e de $14 \%$ de uso e 9\% de concordância em Lages.

E, por fim, o subsistema você/tu sem concordância deixa de ser apresentado somente na região Sul, ocorrendo em todas as outras regiões do país. Os percentuais de uso, nesse subsistema, podem variar nas formas você/cheloce e tu dependendo das variáveis, como a interação e o gênero do falante, porém, o papel do contexto interacional na escolha do você ou do tu pode variar de acordo com o tipo de coleta realizado. No estudo realizado por Modesto (2006) na cidade de Santos, foram observadas diferenças em relação ao tipo de gravação, ou seja, gravações ocultas e não ocultas. Neste caso, apesar de não ser possível separar as duas amostras, houve um registro médio de $29 \%$ de uso do $t u$, que variou entre $17 \%$ a $46 \%$. Vale lembrar também que, nesse subsistema, não há concordância com o pronome tu e geralmente ele não é a primeira opção dos falantes. Como podemos observar no exemplo (3).

F1: ... e o ruim é que... tem as estrelinha né... eu nunca cheguei até a última... pra tu vê né eu já zoei naquele jogo e eu nunca cheguei até a última... se eu chegar acho na terceira... que acontece o helicóptero começa a vim... ai o helicóptero só começa a te metralhar se você... atirar nele... começa a te dar...ordem de prisão.. aí se você atirar ele começa a te metralhar... ai se tu piorar a coisa... começa a descer carinha... da... tipo da swat lá... (MODESTO, 2006, p. 77)

Como podemos observar, existem diversos estudos sobre a variação da segunda pessoa do singular em todo o país, porém, não existe um padrão e, em cada região, existe a predominância de uma ou outra forma que são condicionadas a partir de fatores linguísticos e sociais. Mota (2008), ao analisar a variação no português oral de São João da Ponte, no estado de Minas Gerais, constatou que a variação entre tu/você depende da alternância entre o estilo formal e informal, assim como a relação entre os interlocutores. 
Modesto (2006), assim como Mota (2008), em sua pesquisa na cidade de Santos, no estado de São Paulo, nos mostra que a variação acontece a depender se a situação é mais ou menos informal, aparecendo o tu nas situações mais informais, porém, seu uso não supera a utilização do tu pelos Santistas, que supera o tu com um grande percentual de diferença.

Através do mapeamento exposto, podemos observar que a variação das formas pronominais de $2^{\mathrm{a}}$ pessoa do singular ocorre em todo o território nacional, mostrando que, apesar de não constar nas gramáticas tradicionais como pronome de $2^{\mathrm{a}}$ pessoa do singular (BECHARA, 2008; CUNHA; CINTRA, 2008), o você está presente na fala dos brasileiros, sendo inclusive usado de forma mais generalizada que o pronome $t u$, que também tem seu uso presente em grande parte do país. Também podemos perceber que, apesar do mapeamento realizado por Scherre et al. (2015) abranger todas as regiões do país, alguns estados não apresentam dados, ou seja, neles não existem estudos relacionados a este fenômeno, como é o caso, por exemplo, do estado de Alagoas. Tentando suprir essa lacuna, analisamos a realização dos pronomes de $2^{\mathrm{a}}$ pessoa do singular na posição de sujeito na língua usada no sertão de Alagoas.

\section{Aporte teórico-metodológico}

Para a descrição e análise dos dados, recorremos à Sociolinguística Variacionista (LABOV, 2008) que trata da variação e da mudança linguística, contemplando os usos variáveis de fenômenos linguísticos em seu contexto social. Tal proposta distancia-se dos estudos linguísticos que consideram a língua como um sistema de normas abstratas, externa ao falante e independente do contexto social e mostra que é na heterogeneidade da língua que se deve buscar a estrutura e o funcionamento desse sistema, defendendo a ideia de que a língua é dotada de uma heterogeneidade sistemática.

Para a análise da variação dos pronomes $t u / v o c \hat{e} / c \hat{e}$ na posição de sujeito no sertão alagoano, também recorremos ao banco de dados do projeto A Lingua Usada no Sertão Alagoano (Lusa), que registra a fala dos sertanejos alagoanos por meio de entrevistas sociolinguísticas coletadas no ano de 2015. O projeto Lusa conta com um banco de dados composto por 96 entrevistas de informantes naturais de cidades do sertão alagoano e estão estratificadas de acordo com as variáveis sociais sexo/gênero (masculino e feminino), faixa 
etária (15-29 anos, 30-44 anos e acima de 44 anos) e escolaridade (analfabeto, ensino fundamental, ensino médio e ensino superior).

Para a análise estatística dos dados, utilizamos o programa computacional GoldVarb X (SANKOFF; TAGLIAMONTE; SMITH, 2005), que "mede os efeitos, bem como a significância dos efeitos, dessas variáveis independentes sobre a ocorrência das realizações da variável que está sendo tratada como dependente" (GUY; ZILLES, 2007, p. 105) e controlamos as seguintes variáveis linguísticas e sociais: paralelismo formal, tipo de discurso, tipo de referencia, sexo/gênero, escolaridade e faixa etária.

\section{Descrição e análise dos dados}

\section{Variável Dependente}

Ao estabelecermos a referência de segunda pessoa do singular na posição de sujeito como variável dependente, elencamos as possíveis variantes presentes na comunidade de fala, a saber, tu, você e cê. Porém, ao realizarmos o levantamento das ocorrências de cada variante na amostra do banco de dados do Projeto Lusa, percebemos que, diferentemente de nossa hipótese de que haveria a variação entre $t u / v o c \hat{e} / c \hat{e}$, houve somente três realizações da forma pronominal $t u$, como podemos observar nos exemplos (4), (5) e (6). Sendo assim, optamos por analisar apenas a variação entre o pronome você e sua variante cê.

(4) Depois tu vai editá é? L9

(5) Armaria tu é doido é? L19

(6) Eu lembro que naquela ladeira ali embaixo que tu conhece né? L96

No entanto, antes da apresentação de nossa análise, faz-se necessário tecer algumas considerações para tentar entender o motivo do tu aparecer em poucas realizações. Sabemos que os estudos sobre a variação de segunda pessoa do singular tendem a apresentar um percentual maior do tu em contextos que proporcionem uma maior interação e intimidade entre o falante e seu interlocutor. Porém, na amostra do Projeto Lusa não foi possível estabelecer tal relação, tendo em vista que ela seguiu o molde de entrevistas sociolinguísticas proposto por Labov (2008). 
Por se tratar de uma entrevista que seguiu um questionário pré-estabelecido, não houve uma grande interação entre o entrevistador e o entrevistado, assim, pensamos que esse fator, somado ao uso do gravador, tenha levado o entrevistado a exercer determinado monitoramento. Em situação semelhante, Paredes Silva (2003), Modesto (2006) e Mota (2008) também registraram baixo índice do pronome tu em entrevistas não secretas, apresentando índices de realização do $t u$ de apenas 10\% em Mota (2008), 32\% em Modesto (2006) e 6\% em Paredes Silva (2003).

Scherre et al. (2015) também ressaltam as limitações encontradas ao realizar estudos sobra a variação tu e você a partir de entrevistas sociolinguísticas, enfatizando que apesar das entrevistas terem como objetivo captar a fala espontânea do entrevistado, em alguns casos isso não acontece, podendo assim não refletir toda a realidade dos usos da língua por muitas vezes o entrevistado evitar trocas de turno ou por não ter de forma natural toda a gama de relações interacionais. Porém, as autoras confirmam que "qualquer coleta de dados é sempre um pequeno recorte da realidade" (SCHERRE et al. 2015, p. 135), e que a baixa realização de $t u$ em bancos de dados sociolinguísticos pode ser um indício de que esse pronome não seja a primeira forma da comunidade.

Com todos os problemas inerentes ao registro dos pronomes de segunda pessoa, teremos a oportunidade de ver que o pronome " $t u$ " é mais difícil de captar em áreas em que ele não parecer ser a primeira forma da comunidade, como, por exemplo, no Rio de Janeiro e em Brasilia. No Rio Grande do Sul, por sua vez, o " $t u$ " emerge com facilidade e naturalidade, mesmo em entrevistas sociolinguísticas (SCHERRE et al. 2015, p. 135).

Em relação à variação você e cê na língua usada no sertão alagoano, após a análise e rodada dos dados, obtivemos um total de 506 realizações, que estão distribuídas da seguinte forma: 473 realizações de você e 33 realizações de cê, como podemos observar nos exemplos (7), (8), (9) e (10). Esses dados não só representam percentuais $94 \%$ de você contra apenas $6 \%$ de $c \hat{e}$, como podemos observar no gráfico 1 , como também mostram que, na comunidade estudada, você é a variante pronominal preferida para representar a segunda pessoa do singular na posição de sujeito.

(7) É fazê de conta que num tá fazendo nada porque se você fize alguma co::isa você só leva prejuízo. L37 
(8) Olhe: - assim - umas é tipo quando você qué viajá sua viaje tem que sê muito bem programada então sempre fazia o seguinte - eu sempre via na internet os lugares assim - geralmente mais visita:dos - né? L58

(9) É muito preocupante primêro não temos um policiamento adequedo cê vê uma cidade como essa cê tem o que? L47

(10) Com dinheiro e: e prestação de conta essas coisa cê tem que tê muito cuidado. L60

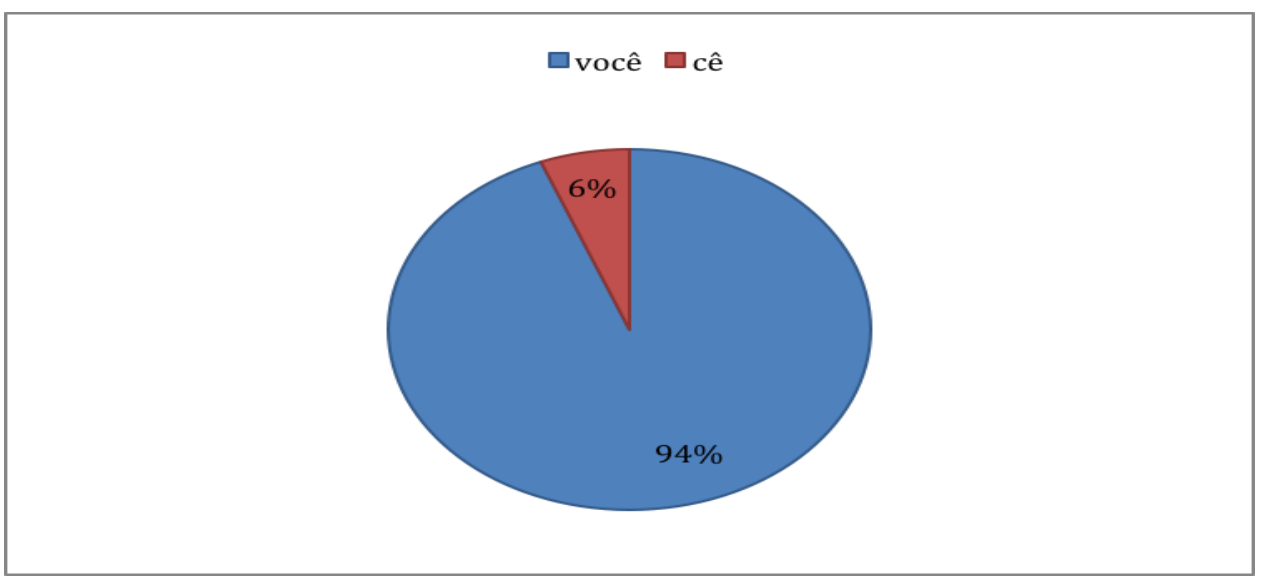

Gráfico 1: distribuição geral de você e cê.

Esses resultados, segundo Labov (2003), apresentam dados que definem a variação em estudo como uma regra variável ${ }^{4}$. No entanto, o baixo percentual de realização da variante cê no sertão de Alagoas fica no limite estabelecido pelo autor para o estabelecimento dessa regra, o que o leva a hipotetizar que o baixo percentual de uma forma variante pode ocorrer por dois motivos, a saber, ou a variante está se implementando na comunidade de fala ou a variante está entrando em desuso através de um processo de mudança linguística.

No caso da realização de $c \hat{e}$, acreditamos que estamos diante de uma variante que começa a se implementar na comunidade de fala do sertão de Alagoas, tendo em vista que estudos sociolinguísticos tendem a mostrar a variação você e cê em algumas variedades do português brasileiro (NOGUEIRA, 2013; ROCHA; SANTOS; SOUSA, 2016;

\footnotetext{
${ }^{4}$ Segundo Labov (2003), há três tipos de regras linguísticas, a saber, regra categórica que apresenta uma frequência de $100 \%$, regra semicategórica que apresenta frequência entre $95-99 \%$ e regra variável que apresenta frequência entre 5-95\%.
} 
GUIMARÃES, 2014), porém precisamos controlar melhor o contexto da entrevista sociolinguística, uma vez que o cê se caracteriza como uma variante relacionada ao uso mais informal da língua.

Em relação aos grupos de fatores potencialmente relevantes na variação você e cê na posição de sujeito na língua usada no sertão alagoano, duas variáveis foram consideradas estatisticamente significativas, seguindo a ordem de relevância do GoldVarb X, a saber, escolaridade e paralelismo formal.

\section{Escolaridade}

Selecionada como a primeira variável estatisticamente significativa na variação você e cê, a variável social escolaridade tem sido amplamente utilizada em estudos sociolinguísticos por acreditar que a escola exerce grande influência tanto na fala quanto na escrita daqueles que a frequentam (VOTRE, 2013). Em nosso estudo, não só partimos do pressuposto de que a variante você será mais frequente entre os falantes mais escolarizados, como também consideramos os seguintes fatores: analfabeto, ensino fundamental, ensino médio e ensino superior.

\begin{tabular}{|c|c|c|c|c|c|c|c|}
\hline & \multicolumn{4}{|c|}{ VOCÊ } & \multicolumn{3}{|c|}{$\mathbf{C E}$} \\
\hline & Total & Ocorrências & Perc. & PR & Ocorrências & Perc. & PR \\
\hline Analfabeto & 41 & 38 & $93 \%$ & .41 & 3 & $7 \%$ & .59 \\
\hline Ens. Fund. & 84 & 81 & $96 \%$ & .60 & 3 & $4 \%$ & .40 \\
\hline Ens. Médio & 146 & 126 & $86 \%$ & .28 & 20 & $14 \%$ & .72 \\
\hline Ens. Superior & 237 & 230 & $97 \%$ & .62 & 7 & $3 \%$ & .38 \\
\hline
\end{tabular}




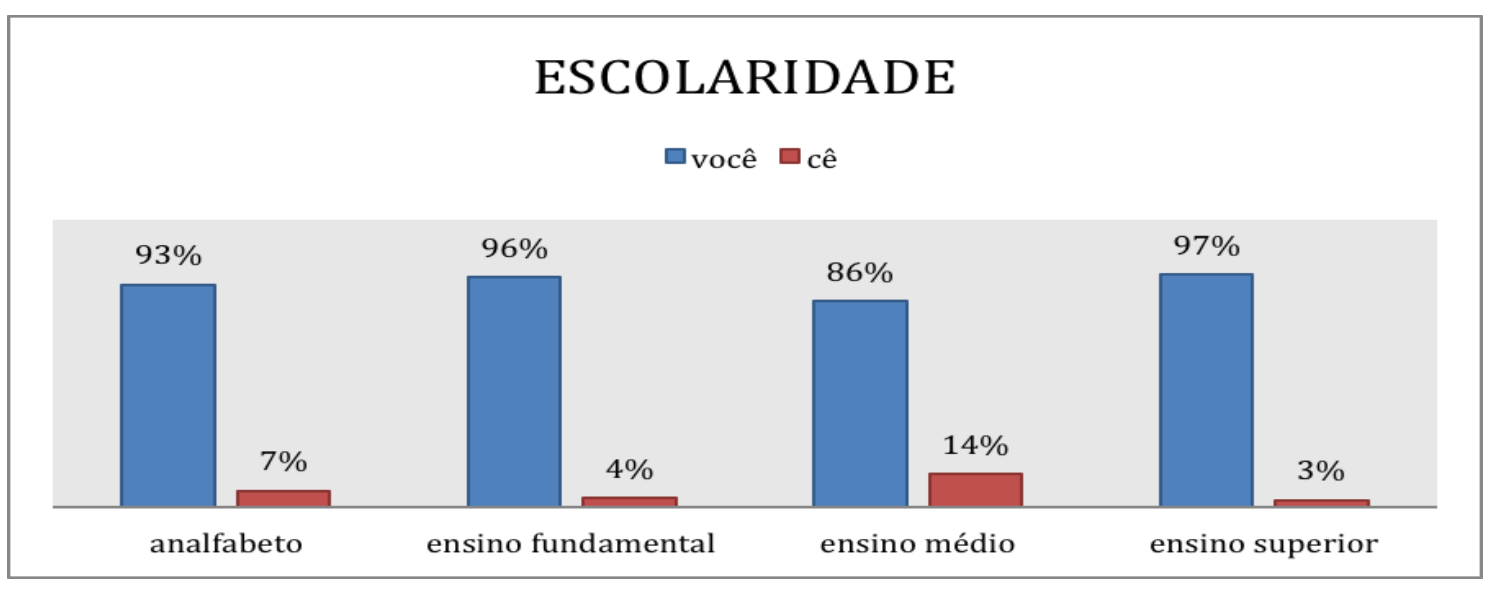

Gráfico 2: percentuais você e cê conforme a escolaridade.

Como podemos observar, a variante você apresenta um percentual, entre os informantes analfabetos, de 93\% de uso com peso relativo .41. Já os informantes de ensino fundamental e ensino superior apresentam um comportamento linguístico bem semelhante, apresentando, respectivamente, percentuais de $96 \%$ e $97 \%$ com peso relativo .60 e .62 , favorecendo, assim, mais a realização do pronome você na comunidade estudada. Os informantes de ensino médio, por sua vez, apresentam um percentual de uso do você menor que os demais, sendo $86 \%$ com peso relativo .28 .

No que diz respeito ao uso da variante cê na comunidade de fala do sertão de Alagoas, podemos constatar um percentual de 7\% com peso relativo .59, em relação aos informantes analfabetos, enquanto os informantes de ensino fundamental apresentam um percentual de 4\% com peso relativo .40 assemelhando-se aos informantes de nível superior que apresentam um percentual de uso de cê de 3\% com peso relativo .38, o que nos mostra, em termos de peso relativo, um desfavorecimento dessa variante. O uso do cê foi constatado com maior percentual de uso entre os informantes de ensino médio, que apresentam um percentual de $14 \%$ com peso relativo .72 .

Assim, podemos perceber que, em nosso estudo, de forma geral, o você apresenta-se com frequência de uso maior em todos os níveis de escolaridade analisados, mostrando-se de maneira semelhante entre eles, oscilando apenas entre os informantes de ensino médio que apresentam um percentual de você menor que os demais e assim favorece mais a realização da variante $c \hat{e}$.

O estudo de Loregian-Penkal e Menon (2012) realizado em Curitiba apresenta resultados semelhantes ao nosso no que diz respeito à escolaridade; nele podemos observar 
que o cê também é realizado com maior frequência entre os informantes de ensino médio, mostrando, assim, que esse nível de escolarização tende a favorecer mais o uso da variante cê.

\section{Paralelismo formal}

A segunda variável selecionada como significativa estatisticamente para o programa foi o paralelismo formal. De acordo com Omena (1996, 2003) e Lopes (1998), o paralelismo formal diz respeito à tendência de o falante repetir a mesma forma na sequência de seu discurso, considerando que a escolha de uma forma condiciona as realizações seguintes dela, ocasionando a repetição da mesma forma pronominal. O estudo de Loregian-Penkal e Menon (2012) demonstra que há uma tendência de os pronomes manterem o princípio geral do paralelismo, ou seja, acredita-se que uma marca leva à repetição dela no decorrer do discurso.

Para análise desta variável, selecionamos os fatores realização isolada, quando apenas uma forma aparece no discurso, como podemos observar no exemplo (11), primeiro da série, como a forma que aparece primeiro no discurso seguida das demais, como podemos observar no exemplo (12), antecedido por você, quando a forma seguinte é antecedida pelo pronome você, como podemos observar no exemplo (13), e antecedida por $c \hat{e}$, quando a forma seguinte é antecedida pelo cê, como podemos observar no exemplo (14).

(11) Aqui você sai e chega Maria Bode - quem conhece Maria Bode vai até Maria Bode aí tem o trevo né. L25

(12) Olha pra você seguí a profissã::o é só você tê força de vontade -- só que exige muito - o seu dia a dia é um dia a dia muito corrido. L39

(13) É::: - denunciando - a denúncia é a maió na minha opinião - a maió das ideas é você denunciá é você não ficá calado - você é: se concientizá e tentá fezê tudo no coletivo - tenta procurá. L48

(14) É melhó cê tá ganhano o normal aqui do que cê tá ganhano mais um pôco no mei do mundo que é mais gasto. L73 


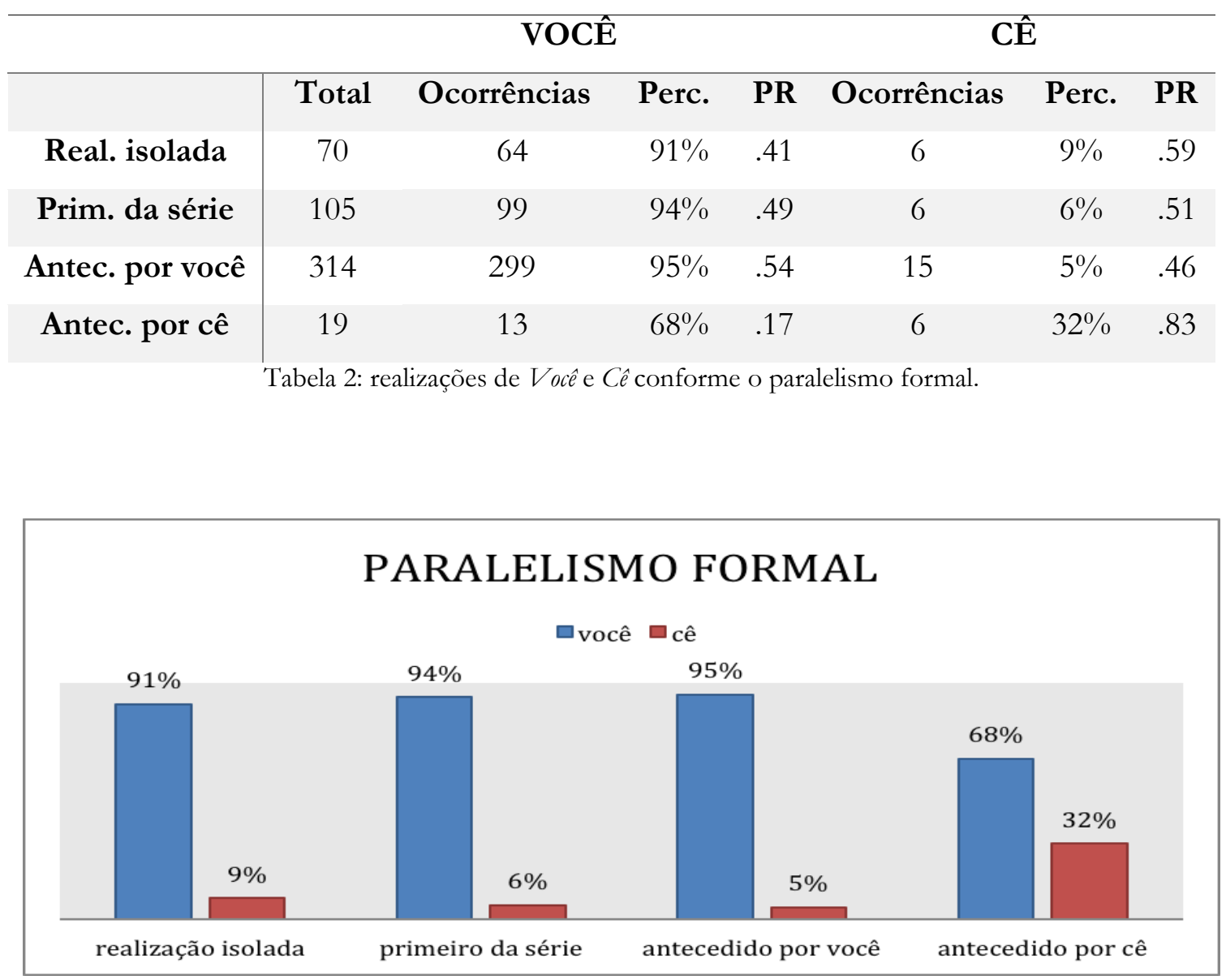

Gráfico 3: percentuais você e cê conforme o paralelismo formal.

Após a análise estatística dos dados, podemos observar que você apareceu com maior frequência no fator antecedido por você, como podemos observar no exemplo (15), totalizando $95 \%$ de realizações com peso relativo .54 e o cê apareceu com maior número de ocorrências no fator antecedido por cê, como podemos observar no exemplo (16), totalizando $32 \%$ das realizações com peso relativo .83 . Assim, mantemos o princípio geral do paralelismo, como afirma Loregian-Penkal (2004), que uma marca tende a levar a repetição da mesma marca na sequência discursiva.

(15) Então independente do que você faça que você faça sempre o melhó - seja como professo::ra ou como qualqué outra profissão. L63

(16) Vale a pena cê conhecê que cê viajá quem gosta principalmente quem gosta de viajá vale a pena e que pode também né porque muitas vezes gosta e não pode. L79 
Os fatores realização isolada e primeiro da série apresentaram, respectivamente, percentuais de $91 \%$ com peso relativo .41 e $94 \%$ com peso relativo .49 em você, como podemos observar nos exemplos (17) e (18). Em termos de peso relativo, podemos afirmar que o fator realização isolada desfavorece o uso de você e o fator primeiro da série fica dentro da escala de neutralidade.

(17) Agora assim a segurança você vai pergunta /mais, mas/, na frente aí né? L15

(18) Porque si você conhecesse Delmiro Gouveia: - há anos atrás quando ele não administrava - você não reconheci Delmiro Gouveia hoje. L71

Em relação ao uso do $c \hat{e}$, o fator realização isolada apresentou percentual de $9 \%$ com peso relativo .59, como podemos observar no exemplo (19), favorecendo também o uso dessa variante, e o fator primeiro da série apresentou um percentual de $6 \%$ com peso relativo .51, como podemos observar no exemplo (20), apresentando-se, assim, dentro da escala de neutralidade.

(19) Ave: Maria agora aí cê me pegou porque a violência tá demais - a violência tá que só Jesus na cau:sa só Deus na causa esse sim porque ele acaba tu:do. L90

(20) Aí né cê sa::be é o único passeio que eu vô - eu não tenho pra onde ir -- as:: ve::z assi::m eu peço a pai::nho pa ir uma festi::nha assim - porque você sabe né que arrente ainda tem que pedi::r. L19

Sendo assim, de acordo com os resultados obtidos, percebemos que tanto para você quanto para $c \hat{e}$, a escolha da primeira forma pronominal é responsável pelo condicionamento da forma subsequente, o que gera uma série de repetições, ou seja, há uma tendência na língua de que as formas iguais ocorrem na mesma sequência discursiva. Desta forma, se um falante inicia seu discurso com você, a tendência é que ele continue usando o mesmo pronome nas realizações seguintes e o mesmo processo tende a ocorrer com o uso da variante cê.

Dessa forma, percebemos que nossos resultados corroboram com os resultados obtidos por Rocha et al. (2016) que estudaram a variação você/cê na cidade de Vitória da Conquista - BA. Nesse estudo o pronome você foi mais frequente quando antecedido por você e o cê foi mais frequente quando antecedido por $c \hat{e}$, mostrando que há uma grande tendência de que as marcas se repitam em uma dada sequência do discurso. 


\section{Considerações finais}

Em nosso estudo, analisamos as realizações dos pronomes de segunda pessoa do singular $t u / v o c \hat{e}$ e você/cê na posição de sujeito na fala dos sertanejos alagoanos, objetivando descrever como essas variações ocorrem na comunidade de fala pesquisada. Ao partimos do pressuposto de que as variações tu/você e você/cê ocorrem em função de condicionamentos linguísticos e sociais, recorremos aos pressupostos teóricometodológicos da Teoria da Variação e Mudança linguística (LABOV, 2008).

Para atingir nossos objetivos, utilizamos a amostra do Projeto Lusa (A língua usada no sertão alagoano) que é composta por 96 entrevistas estratificadas de acordo com as variáveis independentes sexo/gênero, faixa etária e escolaridade. Ao analisarmos os dados, obtivemos apenas três realizações do pronome $t u, 473$ realizações do pronome você e 33 realizações da sua variante cê. Assim, optamos por analisar somente a relação entre as variantes você e cê. Ao todo, tivemos 506 realizações da variação estudada, que foram estatisticamente tratadas pelo programa computacional GoldVarb X.

A partir da análise estatística dos dados, constatamos que, na fala dos sertanejos alagoanos, há a variação você/ cê, porém, em distribuição geral, nossos resultados mostraram um percentual de realizações de $94 \%$ do pronome você e $6 \%$ de realizações da sua variante cê. Apesar do baixo percentual de realização da variante cê, nossos resultados apresentam, segundo Labov (2003), uma regra variável, o que nos leva a acreditar que o uso de cêainda está se implementando na comunidade de fala estudada.

Também podemos constatar que a variação você/ cê não ocorre de maneira aleatória, mas sim condicionada por grupos de fatores linguísticos e sociais. Entre os grupos de fatores sociais e linguísticos selecionados para a realização deste estudo, apenas o grupo social escolaridade e o grupo linguístico paralelismo formal foram considerados pelo programa como estatisticamente significativos. Sendo os grupos de fatores sexo/gênero, faixa etária, tipo de referência e tipo discurso, selecionados como estatisticamente não significativos pelo programa.

Amplamente utilizada nos estudos sociolinguísticos, a variável social escolaridade foi a primeira a ser selecionada pelo programa como significativa. Dessa forma, a variável apresentou o pronome você com maior frequência em todos os níveis de escolaridade, porém, a variante cê apresenta-se com um percentual mais elevado entre os informantes de 
ensino médio, o que nos mostra que esse nível de escolarização tende a favorecer a variante $c \hat{e}$.

A variável linguística selecionada foi o paralelismo formal que, em todos os fatores, apresentou um percentual mais elevado do pronome você. Porém, ao observarmos a relação entre os grupos de fatores, percebemos que o você apareceu com maior percentual no fator antecedido por você, enquanto o cê mostrou-se com percentual mais elevado no fator antecedido por cê. O que nos leva a perceber que, como afirma Loregian-Penkal (2004), uma marca leva a repetição da mesma marca.

Em relação ao encaixamento do nosso estudo nos subsistemas apresentados por Scherre et al. (2015), acreditamos que a nossa pesquisa se enquadra no sexto subsistema apresentado pelos autores, a saber, o subsistema você/tu sem concordância, no qual faz parte o uso das formas você/chelocê e $t u$ - com $t u$ de $1 \%$ a $90 \%$ sem concordância, uma vez que nosso estudo apresentou variação entre você e che, como também apresentou três realizações da forma pronominal tu na amostra analisada.

Esperamos ter contribuído para o entendimento do uso das formas pronominais de $2^{\mathrm{a}}$ pessoa do singular no sertão alagoano, de forma a contribuir para a compreensão de sua distribuição na comunidade pesquisada. Esperamos também que os resultados aqui apresentados possam contribuir para os estudos na área de sociolinguística e servir de auxílio para pesquisas referentes ao uso da língua e principalmente ao mapeamento sociolinguístico do PB (MARTINS; ABRACADO, 2015).

\section{Referências}

ALVES, C. O uso do tu e do você no português falado do Maranhão. Dissertação (Mestrado em Linguística). Fortaleza: Universidade Federal do Ceará, 2010.

ANDRADE, A. A variação você, cê, ocê no português brasileiro falado. Dissertação (Mestrado em Linguística). Brasília: Universidade de Brasília, 2004.

BECHARA, E. Moderna gramática portuguesa. 37. ed. Rio de Janeiro: Lucerna, 2008.

CAMPOS, B. M. S. P. Alteamento vocálico em posição pretônica no português falado no município de Mocajuba - Pará. Dissertação (Mestrado em Letras). Salvador: Universidade Federal da Bahia, 2006. 
CUNHA, C.; CINTRA, L. Nova gramática do português contemporâneo. 4. ed. Rio de Janeiro: Lexicon, 2008.

DIAS, E. O uso do tu no português brasiliense falado. Dissertação (Mestrado em Linguística). Brasília: Universidade de Brasília, 2007.

GUIMARÃES, T. TU É DOIDO, MACHO! A variação das formas de tratamento no falar de Fortaleza. Dissertação (Mestrado em Linguística Aplicada). Fortaleza: Universidade Estadual do Ceará, 2014.

GUY, G.; ZILLES, A. Sociolinguística quantitativa: instrumental de análise. São Paulo: Parábola Editorial, 2007.

HERÊNIO, K. “Tu” e "você" em uma perspectiva intralinguística. Dissertação (Mestrado em Linguística). Uberlândia: Universidade Federal de Uberlândia, 2006.

ILARI, R. et al. Os pronomes pessoais do português falado: roteiro para análise. In: CASTILHO, A. T.; BASÍLIO, M. (Org.). Gramática do português falado. São Paulo: Unicamp, 1996.

LABOV, W. Padrões sociolinguísticos. São Paulo: Parábola Editorial, 2008 [1972].

Some sociolinguistc principles. In: PAULSTON, C.; TUCKER, G. (Org.). Sociolinguistic: the essential readings. Massachusetts: Blackwell Publishing, 2003.

LOPES, C. Nós e a gente no português falado culto do Brasil. DELTA, v. 14, nº 2, 1998.

LOREGIAN-PENKAL, L. (Re)análise da referência de segunda pessoa na fala da região Sul. Tese (Doutorado em Letras). Curitiba: Universidade Federal do Paraná, 2004.

LOREGIAN-PENKAL, L.; MENON, O. Você, Ocê (?) e Cê em Curitiba, Paraná. Signum: Estudos Linguísticos, n 15, 2012.

MACHADO, A. C. M.. As formas de tratamento no teatro brasileiro e português dos séculos XIX e XX. Tese (Letras Vernáculas). Rio de Janeiro: Universidade Federal do Rio de Janeiro, 2011.

MARTINS, M.; ABRAÇADO, J. Mapeamento sociolinguístico do português brasileiro. São Paulo: Contexto, 2015.

MODESTO, A. Formas de tratamento no português brasileiro: a alternância "tu/você" na cidade de Santos-SP. Dissertação (Mestrado em Filologia e Língua Portuguesa). São Paulo: Universidade de São Paulo, 2006.

MOTA, M. A variação dos pronomes 'tu' e 'você' no português oral de São João da Ponte (MG). Dissertação (Mestrado em Linguística). Belo Horizonte: Universidade Federal de Minas Gerais, 2008.

NOGUEIRA, F. M. S. B. Como os falantes de Feira de Santana e Salvador tratam o seu interlocutor? Dissertação (Mestrado em Língua e Cultura). Salvador: Universidade Federal da Bahia, 2013. 
OMENA, N. A referencia à primeira pessoa do discurso no plural. In: OLIVEIRA e SILVA, M.; SCHERRE, M. (Org.). Padrões sociolinguísticos: estudos de fenômenos variáveis do português falado do Rio de Janeiro. Rio de Janeiro: UFRJ Editora, 1996.

A referencia à primeira pessoa do discurso no plural. In: PAIVA, M.; DUARTE, E. (Org.). Mudança linguística em tempo real. Rio de Janeiro: Contra Capa, 2003.

PAREDES SILVA, V. O retorno do pronome tu à fala carioca. In: RONCARATI, C; ABRAÇADO, J. (Org.). Português brasileiro: contato linguístico, heterogeneidade e história. Rio de Janeiro: 7 Letras, 2003.

ROCHA, W. J. C.; SANTOS, L. O. S.; SOUSA, V. V. O pronome você e sua variante cê: um estudo (sócio)funcional. Interdisciplinar: Revista de Estudos em Língua e Literatura, v. 24, Jan./Abr. 2016.

SANKOFF, D.; TAGLIAMONTE, S.; SMITH, E. Goldvarb X: a variable rule application for Macintosh and Windows. Departament of Linguístics, University of Toronto, 2005.

SCHERRE et al. Variação dos pronomes "tu" e "você". In: MARTINS, M.; ABRAÇADO, J. (Org.). Mapeamento sociolinguístico do português brasileiro. São Paulo: Contexto, 2015.

SOARES, I.; LEAL, M. Do senhor ao tu: uma conjugação em mudança. MOARA Estudos da Língua em Uso. Revista do Curso de Mestrado em Letras, Universidade Federal do Pará, Belém, no 1, Mar./Set. 1993.

SOUZA, J. P. F.. Mapeando a entrada do Você no quadro pronominal: análise de cartas familiares dos séculos XIX-XX. Dissertação (Letras Vernáculas). Rio de Janeiro: Universidade Federal do Rio de Janeiro, 2012.

VITRAL, L. A forma Cê e a noção de gramaticalização. Revista de Estudos da Linguagem, v. 1, n 4, 1996.

VOTRE, S. J. Relevância da variável escolaridade. In: MOLLICA, Maria Cecília; BRAGA, Maria Luiza (Org.). Introdução à sociolinguística: o tratamento da variação. São Paulo: Contexto, 2013. 


\begin{abstract}
This research analyzes the achievement tu, você and cê in subject position in the alagoano backwoods. For this proposal, we resort the Variational Sociolinguistics (LABOV, 2008) and to the database of the Lusa project and we use the software GoldV arb X for statistical analysis of data. According to the obtained results, we verify that the pronoun tu has only three achievements, which may be an indication that its use is not the community's first choice for the reference to the second person singular in the subject position. In relation to the use of você and cê, we obtained a percentage of $94 \%$ of você versus $6 \%$ of cê, being this variation conditioned by the variables schooling and formal parallelism. These results lead us to argue that, in the alagoano backwoods, the representation of the second person singular in the position of subject fits in the subsystem tu/você without agreement (SCHERRE et al. 2015).
\end{abstract}

Keywords: Sociolinguistics. V ariation. Pronouns.

Speaking. Alagoano backwoods 